\title{
Antibacterial Effects of Natural Herbal Extracts on Streptococcus mutans: Can They Be Potential Additives in Dentifrices?
}

\author{
Spoorthi Banavar Ravi, ${ }^{1}$ Sudarshini Nirupad, ${ }^{2}$ \\ Prashanthi Chippagiri, ${ }^{3}$ and Rohit Pandurangappa ${ }^{1}$ \\ ${ }^{1}$ School of Dentistry, International Medical University, No. 126, Jalan 19/155B, Bukit Jalil, Kuala Lumpur, Malaysia \\ ${ }^{2}$ Oral Pathology, Dr. Syamala Reddy Dental College Hospital and Research Centre, SGR College Main Road, Marathahalli Post, \\ Bangalore, Karnataka, India \\ ${ }^{3}$ Faculty of Dentistry, MAHSA University, Kuala Lumpur, Malaysia
}

Correspondence should be addressed to Spoorthi Banavar Ravi; drspoorti@gmail.com

Received 19 June 2017; Revised 21 August 2017; Accepted 25 September 2017; Published 19 October 2017

Academic Editor: Izzet Yavuz

Copyright (C) 2017 Spoorthi Banavar Ravi et al. This is an open access article distributed under the Creative Commons Attribution License, which permits unrestricted use, distribution, and reproduction in any medium, provided the original work is properly cited.

\begin{abstract}
Background. Many plants or herbs exhibit potent antimicrobial activity against various microorganisms. They have no side effects and presumably act against and modulate the factors that are crucial for microbial survival or their activity. Streptococcus mutans is a pioneer bacteria implicated in dental caries. This study aims to evaluate the antimicrobial activity of garlic bulbs, pudina leaves, and mango and eucalyptus twig extracts on Streptococcus mutans by evaluating their zone of inhibition and determining their minimum inhibitory concentration (MIC). Methods. Microbiological assay (well diffusion method) to determine zone of inhibition against pure forms of Streptococcus mutans was performed. The antibacterial effects of methanolic extracts of mango twigs, eucalyptus twigs, pudina leaves, and garlic bulbs were studied. Test compounds were further evaluated for their MIC. Results. Extracts derived from mango and eucalyptus twigs showed significant antibacterial effects at test concentrations. Pudina and garlic extracts did not show any significant antibacterial effects at similar concentrations. Upon further evaluation of the 2 positive compounds for their MIC, mango twigs demonstrated more antimicrobial potential than eucalyptus twigs at a lower concentration. Conclusion. Our observations indicated that the mango twig extracts possess higher antibacterial effects against Streptococcus mutans than other compounds at specific test concentration.
\end{abstract}

\section{Introduction}

Dental caries is a chronic microbial disease affecting humans in all parts of the world $[1,2]$. mutans group of streptococci, being the active cause of caries $[3,4]$, produce weak organic acids after fermenting carbohydrates, or a byproduct resulting in demineralization of the tooth structure $[5,6]$. Preventing and controlling dental caries has been a great challenge. For ages many prophylactic agents have been used to prevent dental caries such as antibiotics, plant and herb derived compounds, mouth washes, tooth pastes, gels, varnishes, and the caries vaccines [7]. One such method practiced from an age-old time is use of natural herbs especially by rural people to clean their teeth. In our study, we aimed at evaluating the antimicrobial potential of natural herbs like garlic (Allium sativum), pudina (Mentha arvensis), mango (Mangifera indica) twigs, and Eucalyptus (globulus Labill., nilgiri) twigs on S. mutans.

\section{Materials and Methods}

The materials procured for this in vitro test compounds were garlic lobes, pudina leaves, mango twigs, and eucalyptus twigs. The test bacteria were Streptococcus mutans ATCC 2517 (American-type culture collection). Mueller Hinton agar plate and Tecan plate reader were used. 
2.1. Preparation of Alcoholic Extract of Test Compound. Preparation of alcoholic extract of each test compound was done using $10 \mathrm{~g}$ of dried and powdered material added to $50 \mathrm{ml}$ methanol and incubated at $50^{\circ} \mathrm{C}$ for 4 hours and then filtered through Whatman filter paper. The supernatant was dried at $80^{\circ} \mathrm{C}$. A thick paste was obtained that yielded approximately $5-7 \%$ of extracts; that is, for $10 \mathrm{~g}$ of test compound it yielded $0.5-0.7 \mathrm{~g}$ or $500-700 \mathrm{mg}$ of extract. The stock preparation was done using $100 \mathrm{mg} / \mathrm{ml}$ in methanol. Standardization was based on the NCCLS (National Committee for Clinical Laboratory Standards) method. The microorganisms, Streptococcus mutans (ATCC 2517), were obtained from American-type culture collection, USA. The inoculum was cell suspension prepared from cultures grown on trypticase soy broth adjusted to $1.2 \times 10^{5}$. The positive control was chlorhexidine mouth wash- $0.2 \%$ [8-11] and ciprofloxacin $250 \mathrm{mg}$ [12] and the negative control was methanol.

The test was carried out in two steps, that is, evaluation of antimicrobial activity by evaluating zone of inhibition by well diffusion method and determination of minimum inhibitory concentration (MIC) as per NCCLS method $[13,14]$.

\subsubsection{Evaluation of Antimicrobial Activity by Zone of Inhibition} by Well Diffusion Method. $100 \mu \mathrm{l}$ inoculum of test bacterial cultures was inoculated on Mueller Hinton agar plates $(90 \mathrm{~mm})$. The test compounds ( $1 \mathrm{mg}$ and $2 \mathrm{mg}, 10-20 \mu \mathrm{L}$ ) and test drugs chlorhexidine $(40 \mu \mathrm{g}, 20 \mu \mathrm{L})$ and ciprofloxacin $(2.5 \mu \mathrm{g}, 20 \mu \mathrm{L})$ were impregnated on $5 \mathrm{~mm}$ wells. The plates were incubated at $35^{\circ} \mathrm{C}$ for $24-48$ hours and observed for zone of inhibition around the well.

2.1.2. Determination of MIC (Minimum Inhibitory Concentration) as per NCCLS Method. The test bacteria, that is, Streptococcus mutans (ATCC 25175), and the test compounds, that is, methanolic extract of eucalyptus twigs and mango twigs, were used at the concentration of $16-1024 \mu \mathrm{g} / \mathrm{ml}$ by twofold dilution method in Mueller Hinton broth. Test drugs were Ciprofloxacin and Chlorhexidine used at the concentrations of $0.25-16 \mu \mathrm{g} / \mathrm{ml}$ and $4-256 \mu \mathrm{g} / \mathrm{ml}$, respectively, by twofold dilution method in Mueller Hinton agar broth. The test compounds and the test drugs (positive control) were diluted for 8 different concentrations by 2 -fold dilution method $[8,9]$. Ninety $\mathrm{ml}$ drug or test compounds of different test concentration was mixed with $10 \mathrm{ml}$ inoculum in 96well plates in triplicate. The control used was $90 \mathrm{ml}$ Mueller Hinton agar without drug mixed with $10 \mathrm{ml}$ inoculum, all incubated at $35^{\circ} \mathrm{C}$. The bacterial test plates were observed after 24-48 hours. Optical density (OD) of $600 \mathrm{~nm}$ was measured in a Tecan plate reader. MIC (minimum inhibitory concentration) was determined at $50 \%$ inhibition of OD as compared with control.

\section{Results}

The zone of inhibition was observed against positive controls and test sample after incubating at $35^{\circ} \mathrm{C}$ for $24-48$ hours (Figure 1). The mango and eucalyptus twig extracts clearly showed larger zone of inhibition in comparison with

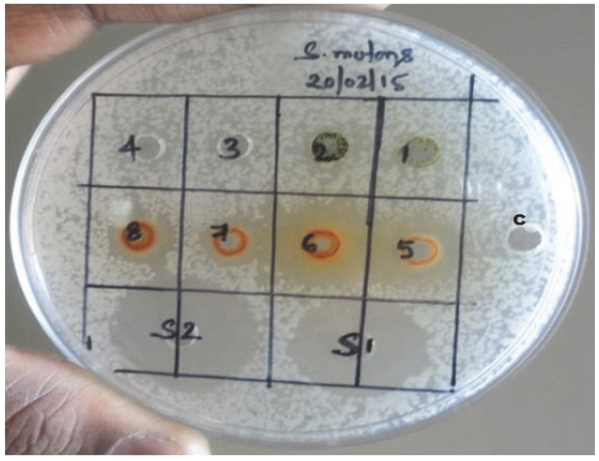

FIGURE 1: Inhibitory activity of test samples on Streptococcus mutans. Test extracts: (1) pudina ( $1 \mathrm{mg} /$ well), (2) pudina ( $2 \mathrm{mg} /$ well), (3) garlic (1 mg/well), (4) garlic ( $2 \mathrm{mg} /$ well), (5) mango ( $1 \mathrm{mg} /$ well), (6) mango ( $2 \mathrm{mg} /$ well), (7) eucalyptus ( $1 \mathrm{mg} /$ well), (8) eucalyptus $(2 \mathrm{mg} /$ well), S1: chlorhexidine $(40 \mu \mathrm{g} /$ well $)$, S2: ciprofloxacin $(2.5 \mu \mathrm{g} / \mathrm{well})$, and C: methanol control (negative).

TABLE 1: Inhibitory activity of Test samples on Streptococcus mutans.

\begin{tabular}{lcc}
\hline Test compound & $\begin{array}{c}\text { Concentration } \\
(\mathrm{mg} / \text { Well })\end{array}$ & $\begin{array}{c}\text { Zone of inhibition (in mm) } \\
\text { Test organisms } \\
\text { Streptococcus mutans }\end{array}$ \\
\hline Pudina & 1 & - \\
Garlic & 2 & - \\
Mango extract & 2 & - \\
Eucalyptus extract & 1 & $13.5 \pm 0.5$ \\
Chlorhexidine & 2 & $16.0 \pm 1.0$ \\
Standard & 0.040 & $9.5 \pm 0.5$ \\
ciprofloxacin & 0.0025 & $20.0 \pm 0.0$ \\
\hline
\end{tabular}

other test compounds at particular concentration, as indicated/summarized in Figure 1 and Table 1. Mango twig and eucalyptus twig extracts were further evaluated to know their minimum inhibitory concentration (MIC). This was done along with determination of minimum inhibitory concentration of standards (ciprofloxacin and chlorhexidine) against Streptococcus mutans. The MIC observed for ciprofloxacin was at concentration of $0.5 \mu \mathrm{g} / \mathrm{ml}$ and the percentage of inhibition was 79.28 and MIC for chlorhexidine was at concentration of $4.00 \mu \mathrm{g} / \mathrm{ml}$ and the percentage of inhibition noted was 87.50 (Table 2). The MIC recorded for mango twig extract was at concentration $256 \mu \mathrm{g} / \mathrm{ml}$ and the percentage of inhibition was 50.70 and MIC for eucalyptus extract was at concentration $1024 \mu \mathrm{g} / \mathrm{ml}$ and the percentage of inhibition was 90.90 (Table 3, Figures 2 and 3).

\section{Discussion}

Dental caries is an irreversible chronic disease initiated by Streptococcus mutans, a Gram-positive, facultative anaerobic 
TABLE 2: Minimum inhibitory concentration of ciprofloxacin and chlorhexidine against Streptococcus mutans.

\begin{tabular}{lccc}
\hline $\begin{array}{l}\text { Ciprofloxacin } \\
\text { concentration } \\
(\mu \mathrm{g} / \mathrm{ml})\end{array}$ & \% inhibition & $\begin{array}{c}\text { Chlorhexidine } \\
\text { concentration } \\
(\mu \mathrm{g} / \mathrm{ml})\end{array}$ & \% inhibition \\
\hline 0.00 & 0.00 & 0.00 & 0.00 \\
0.25 & 48.91 & 4.00 & 87.50 \\
0.5 & 79.28 & 8.00 & 88.27 \\
1.0 & 81.00 & 16.00 & 91.24 \\
2.0 & 88.30 & 32.00 & 94.79 \\
4.0 & 88.05 & 64.00 & 95.05 \\
8.0 & 94.49 & 128.00 & 96.64 \\
16.00 & 92.65 & 256.00 & 97.71 \\
0.00 & 81.00 & 0.00 & 88.27 \\
MIC & 0.5 & MIC & $<4$ \\
\hline
\end{tabular}

TABLE 3: Minimum inhibitory concentration of mango and eucalyptus twigs extract against Streptococcus mutans.

\begin{tabular}{lcc}
\hline $\begin{array}{l}\text { Concentrations } \\
(\mu \mathrm{g} / \mathrm{ml})\end{array}$ & \multicolumn{2}{c}{ \% inhibition } \\
\hline 00 & 00 & 0.00 \\
16 & 0.00 & 0.00 \\
32 & 18.52 & 0.00 \\
64 & 21.71 & 0.00 \\
128 & 30.57 & 0.00 \\
256 & 50.70 & 4.35 \\
512 & 79.23 & 40.55 \\
1024 & 88.62 & 90.90 \\
MIC & 256 & 1024 \\
\hline
\end{tabular}

microorganism [15]. Preventing and controlling dental caries have been a great challenge for decades. The garlic extract (Allium sativum) can inhibit growth of both Gram-positive and Gram-negative bacteria. The garlic cloves consist of sulfur containing chemicals like allicin, alliin, and ajoene [16]. When the garlic cloves are cut or crushed they release the enzyme alliinase which converts alliin to allicin and allicin is responsible for antibacterial activity [8]. The anticariogenicity of garlic extract was evaluated in previous studies and can inhibit the bacterial growth only when used at higher concentration $[8,9,15,17]$. Pudina or mint leaves are widely used in food and medicines for their flavor and antibacterial effect. Mint leaves are comprised of menthol, menthone, methyl esters, and terpenoids which are responsible for antibacterial effect [18]. Menthol, being the chief component [19], is used in essential oils and ointments [20]. The antibacterial activity of alcoholic extract of pudina leaves was previously evaluated by Chaudhary et al. at three different concentrations, $5 \%$, $10 \%$, and $50 \%$. The zone of inhibition was seen at $10 \%$ and $50 \%$ concentrations [10]. In another study, the alcoholic extract of mint leaves at $10 \mathrm{mg} / \mathrm{ml}$ was more active against microorganism [12]. Antibacterial properties of alkaloid extracts from Callistemon citrinus and Vernonia adoensis

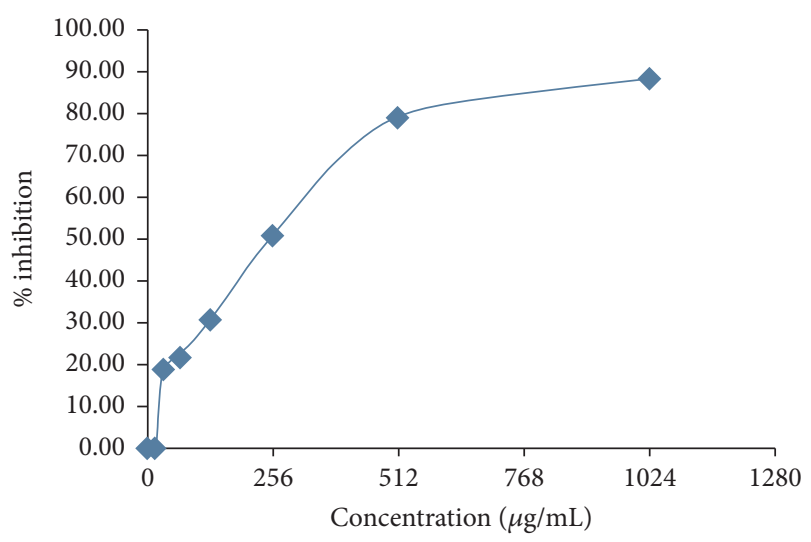

FIGURE 2: Inhibitory activity of mango twigs extracts against $S$. mutans.

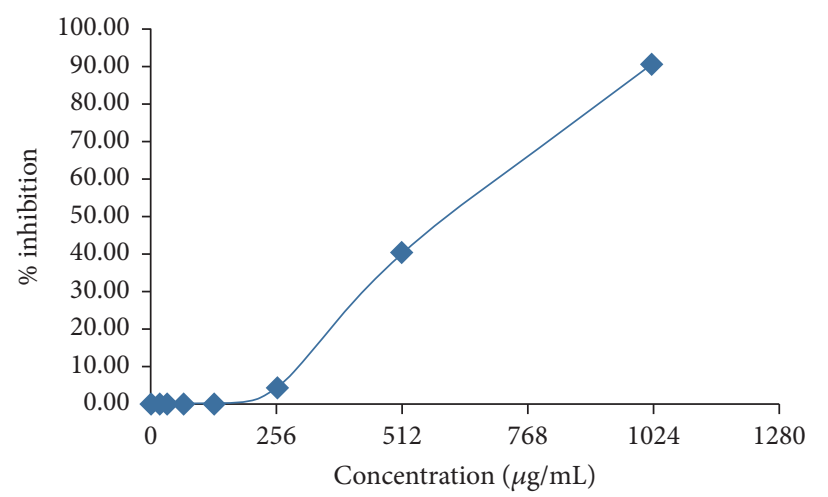

FIGURE 3: Inhibitory activity of eucalyptus twigs extracts against $S$. mutans.

against Staphylococcus aureus and Pseudomonas aeruginosa were evaluated by Mabhiza et al. in 2016 and they reported that alkaloids may serve as potential courses of compounds that can act as lead compounds for the development of plantbased antibacterials and/or their adjunct compounds [21]. In our study, to evaluate the antibacterial effect on Streptococcus mutans we used garlic lobes (Allium sativum) and pudina leaves (Mentha arvensis) alcoholic extract at $1 \mathrm{mg} / \mathrm{ml}$ and $2 \mathrm{mg} / \mathrm{ml}$ concentrations; both the test compounds did not show any antibacterial effect against the cariogenic bacteria. The reason for this could be the low concentration of test extracts that were used ( 1 to $2 \mathrm{mg} / \mathrm{ml}$ ).

Mohammed used eucalyptus leaves and revealed that methanolic extract of Eucalyptus spathulata leaves was more effective in inhibiting Streptococcus mutans compared to gentamycin and nystatin [22]. Eucalyptus spathulata twig consists of ketones like juglone, regiolone, sterol, and flavonoid comprising antibacterial potential [23]. We used methanolic extract of eucalyptus twigs that demonstrated antimicrobial activity against Streptococcus mutans compared to garlic lobes extract and pudina leaves extract.

The Mangifera indica consists of tannins, bitter gum, and resins [24]. The tannins and resins have astringent effect on mucous membrane; they protect enamel by forming layer on it. Prashant et al. used mango twigs as one of the 
test compounds to test the antimicrobial activity of Streptococcus mutans, Streptococcus salivarius, Streptococcus mitis, and Streptococcus sanguis. At 50\% concentration it showed maximum zone of inhibition on Streptococcus mitis [25]. In our study when we used mango (Mangifera indica) and Eucalyptus (globulus Labill.) twig extract, at concentrations of $1 \mathrm{mg} / \mathrm{ml}$ and $2 \mathrm{mg} / \mathrm{ml}$, the mango twig extract showed highest zone of inhibition compared to extract of eucalyptus twig. When further evaluated for minimum inhibitory concentration, mango twig extract showed inhibitory activity at minimum concentration of $256 \mu \mathrm{g} / \mathrm{ml}$ compared to eucalyptus twig methanolic extract which was $1024 \mu \mathrm{g} / \mathrm{ml}$.

The tested compounds Mangifera indica and eucalyptus that showed highest antibacterial activity at minimum concentration can be incorporated in oral rinses, dentifrices, cavity liners, and varnishes to improve oral hygiene and cleanliness. These are easily available and are economical.

The effectiveness of chitosan shell toothpaste white shrimp (Litopenaeus vannamei) in reducing Streptococcus mutans in cases of early childhood caries was evaluated by Achmad and Ramadhany [26], by counting the number of colonies formed before and after using the toothpaste. Their results indicated a significant reduction of the number of colonies of Streptococcus mutans in the case of early childhood caries. Widyagarini et al. [27] in 2016 tried to identify serotypes c and e Streptococcus mutans in child-mother pairs and determine the relationship between serotype of $S$. mutans and dental caries in plaque samples. There was no significant relationship between serotype c/e $S$. mutans and child-mother caries score.

The limitations of our study include that this study was conducted in vitro with the extracts of mango and eucalyptus twigs. The duration of the contact of such extracts with the microorganisms in the oral cavity in vivo is not clear; hence further studies comparing the prevalence of dental caries among users and nonusers of such extracts from the twigs should help elucidate the picture. The tested compounds can be further tested to know their minimal bactericidal concentrations (MBC) to comprehensively understand their efficacy against the most dreaded bacteria causing the dental caries.

\section{Conclusion}

The results of our study indicate that the mango twigs possess the antibacterial effect even at low concentration against the most cariogenic bacteria Streptococcus mutans. It appears that it may be possible to combat Streptococcus mutans to increase the efficacy of the oral hygiene practices by incorporating the mango and eucalyptus twig extracts into dentifrices. However, studies simulating in vivo situations more closely are required to get a clear understanding.

\section{Conflicts of Interest}

The authors declare that they have no conflicts of interest.

\section{References}

[1] J. D. Bader, D. A. Shugars, and A. J. Bonito, "Systematic reviews of selected dental caries diagnostic and management methods," Journal of Dental Education, vol. 65, no. 10, pp. 960-968, 2001.

[2] J. Walter, "Role of Streptococcus mutans in human dental decay," Microbiological Reviews, vol. 50, pp. 353-380, 1986.

[3] R. A. Whiley and D. Beighton, "Current classification of the oral streptococci," Oral microbiology and immunology, vol. 13, no. 4, pp. 195-216, 1998.

[4] S. Hamada and H. D. Slade, "Biology, immunology, and cariogenicity of Streptococcus mutans," Microbiology and Molecular Biology Reviews, vol. 44, no. 2, pp. 331-384, 1980.

[5] E. A. M. Kidd and O. Fejerskov, "What constitutes dental caries? Histopathology of carious enamel and dentin related to the action of cariogenic biofilms," Journal of Dental Research, vol. 83, no. C, pp. C35-C38, 2004.

[6] JD. Featherstone, "The continuum of dental caries-evidence for a dynamic disease process," Journal of Dental Research, vol. 83, pp. 39-42, 2004.

[7] F. Chen and D. Wang, "Novel technologies for the prevention and treatment of dental caries: a patent survey," Expert Opinion on Therapeutic Patents, vol. 20, no. 5, pp. 681-694, 2010.

[8] M. M. Fani, J. Kohanteb, and M. Dayaghi, "Inhibitory activity of garlic (Allium sativum) extract on multidrug-resistant Streptococcus mutans," Journal of Indian Society of Pedodontics and Preventive Dentistry, vol. 25, no. 4, pp. 164-168, 2007.

[9] B. Houshmand, F. Mahjour, and O. Dianat, "Antibacterial effect of different concentrations of garlic (Allium sativum) extract on dental plaque bacteria," Indian Journal of Dental Research, vol. 24, no. 1, pp. 71-75, 2013.

[10] N. J. Chaudhary, C. G. A. Krishnan, K. Thanveer, and H. Shah, "Anti-microbial effect of Pudina extract on streptococcus mutans: in vitro study," Journal of International Oral Health, vol. 4, no. 3, pp. 45-49, 2012.

[11] B. R. Chandrashekar, R. Nagarajappa, R. Singh, and R. Thakur, "An in vitro study on the anti-microbial efficacy of ten herbal extracts on primary plaque colonizers," Journal of Young Pharmacists, vol. 6, no. 4, pp. 33-39, 2014.

[12] D. J. Sunitha, P. Shilpa, A. S. Madhusudan, and S. V. Ravindra, "An in vitro antimicrobial activity of few plant extracts on dental caries microorganisms," International Journal of Applied pharmaceutical sciences and Biological Sciences, vol. 1, no. 3, pp. 294-303, 2012.

[13] National Committee for Clinical Laboratory Standards (NCCLS), "Reference method for broth dilution antifungal susceptibility testing of yeasts: approved standard," in NCCLS document M27-A, vol. 20, p. 24, NCCLS, Wayne, PA, USA, 1997.

[14] National Committee for Clinical Laboratory Standards (NCCLS), "National committee for clinical laboratory standards (nccls) methods for dilution antimicrobial susceptibility tests for bacteria that grow aerobically," in NCCLS document M7-A6, NCCLS, Wayne, PA, USA, 6th edition, 2003.

[15] A. M. Fatemeh, H. Soraya, A. Y. Mohammad, P. Jalal, and S. Javad, "Antibacterial effect of eucalyptus (globulus Labill) and garlic (Allium sativum) extracts on oral Cariogenic bacteria," Journal of Microbiology Research and Reviews, vol. 1, no. 2, pp. 12-17, 2013.

[16] S. Ankri and D. Mirelman, "Antimicrobial properties of allicin from garlic," Microbes and Infection, vol. 1, no. 2, pp. 125-129, 1999. 
[17] K. Sulafa and M. R. E.-S. Jinan, "Garlic extracts and acidogenicity of mutans streptococci," e-Journal of Dentistry Jan, vol. 3, no. $1,2013$.

[18] T. K. Mohanta, J. K. Patra, S. K. Rath, D. K. Pal, and H. N. Thatoi, "Evaluation of antimicrobial activity and phytochemical screening of oils and nuts of Semicarpus anacardium," L.f. Scientific Research and Essay 2007, vol. 2, no. 11, pp. 486-490, 2007.

[19] M. Akram, "Menthaarvensis Linn.: a review article," Journal of Medicinal Plants Research, vol. 5, no. 18, pp. 4499-4503, 2011.

[20] P. Agarwal, L. Nagesh, and Murlikrishnan, "Evaluation of the antimicrobial activity of various concentrations of Tulsi (Ocimum sanctum) extract against Streptococcus mutans: An in vitro study," Indian Journal of Dental Research, vol. 21, no. 3, pp. 357-359, 2010.

[21] D. Mabhiza, T. Chitemerere, and S. Mukanganyama, "Antibacterial Properties of Alkaloid Extracts from Callistemon citrinus and Vernonia adoensis against Staphylococcus aureus and Pseudomonas aeruginosa," International Journal of Medicinal Chemistry and Analysis, vol. 2016, pp. 1-7, 2016.

[22] N. A. Mohammed, "In vitro, antimicrobial activity of leaves extracts of eucalyptus spathulata against streptococcus mutans and candida albicans," Journal of Al Rafidain University College, vol. 33, pp. 1-6, 2014.

[23] K. Takarada, R. Kimizuka, N. Takahashi, K. Honma, K. Okuda, and T. Kato, "A comparison of the antibacterial efficacies of essential oils against oral pathogens," Oral microbiology and immunology, vol. 19, no. 1, pp. 61-64, 2004.

[24] S. A. Muhammad and A. Muhammad, "Significance of chewing sticks (Miswaks) in oral hygiene from a pharmacological viewpoint," JPMA, pp. 89-95, 1981.

[25] G. M. Prashant, G. N. Chandu, K. S. Murulikrishna, and M. D. Shafiulla, "The effect of mango and neem extract on four organisms causing dental caries: Streptococcus mutans, Streptococcus salivavius, Streptococcus mitis, and Streptococcus sanguis: An in vitro study," Indian Journal of Dental Research, vol. 18, no. 4, pp. 148-151, 2007.

[26] H. Achmad and Y. F. Ramadhany, "Effectiveness of Chitosan Tooth Paste from White Shrimp (Litopenaeusvannamei) to Reduce Number of Streptococcus Mutans in the Case of Early Childhood Caries," Journal of International Dental and Medical Research, vol. 10, no. 2, pp. 358-363, 2017.

[27] A. Widyagarini, H. Sutadi, and S. B. Budiardjo, "Serotype c and e streptococcus mutans from dental plaque of child-mother pairs with dental caries," Journal of International Dental and Medical Research, vol. 9, pp. 339-344, 2016. 


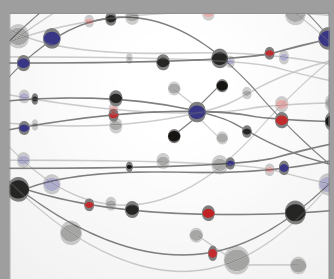

The Scientific World Journal
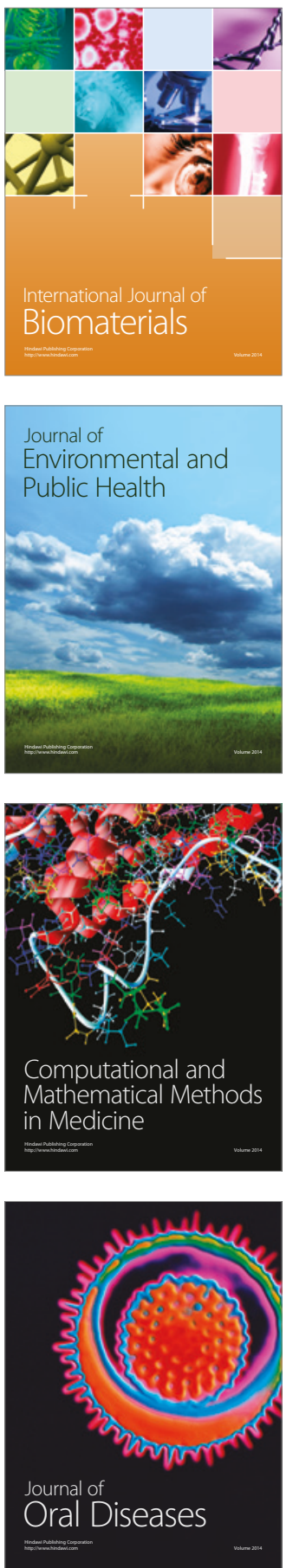
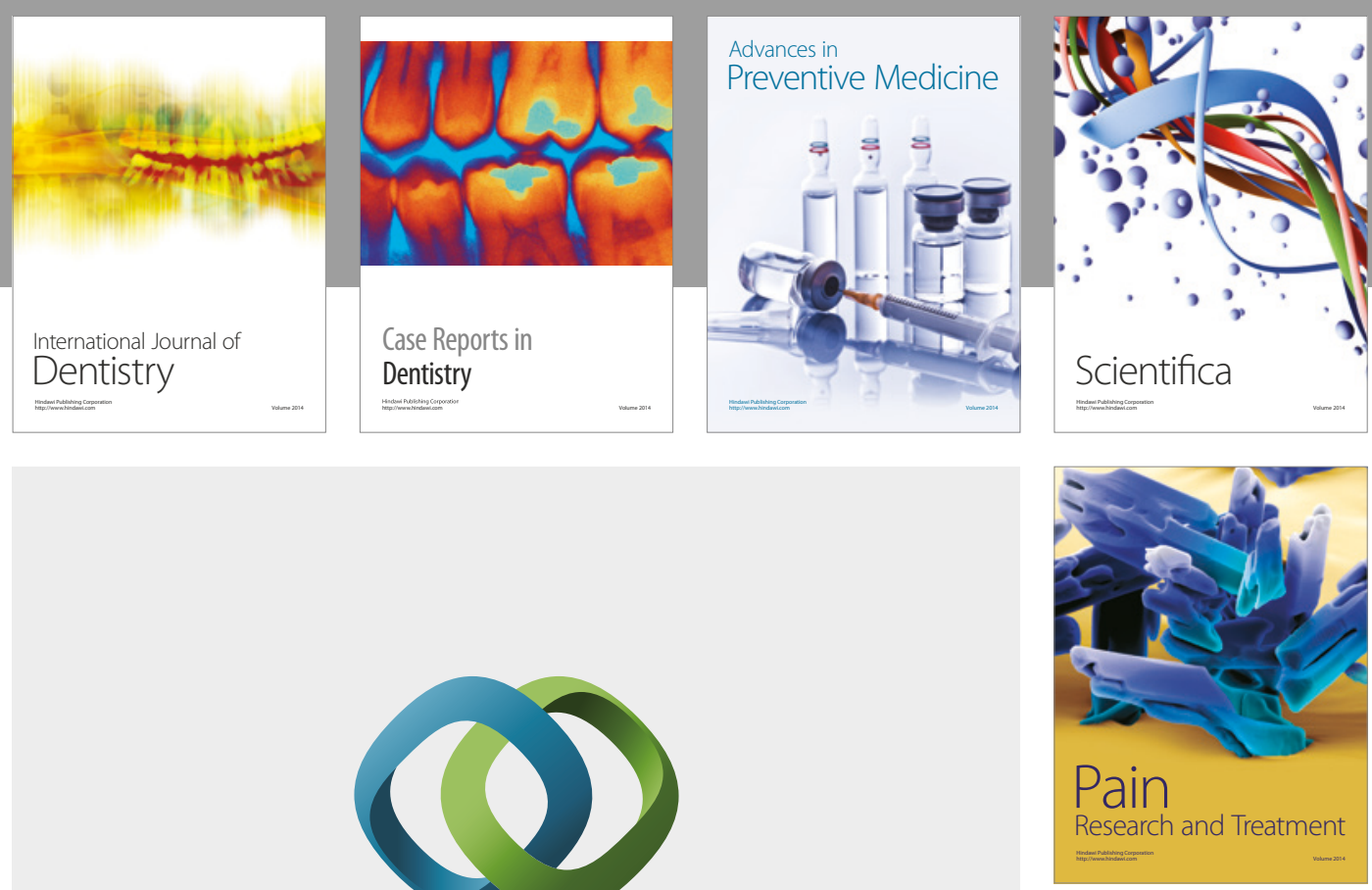

\section{Hindawi}

Submit your manuscripts at

https://www.hindawi.com
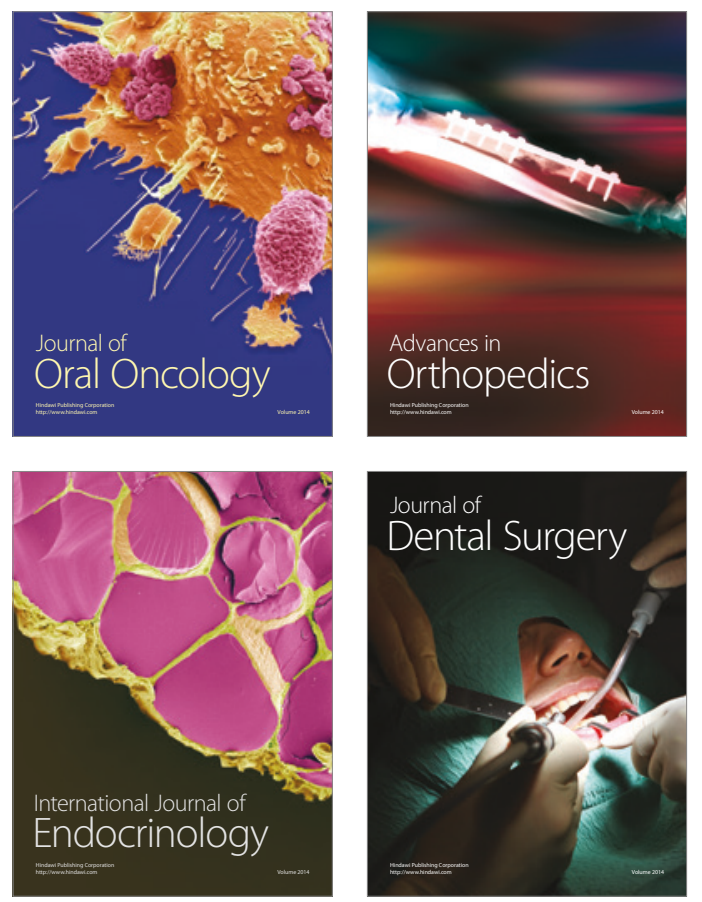
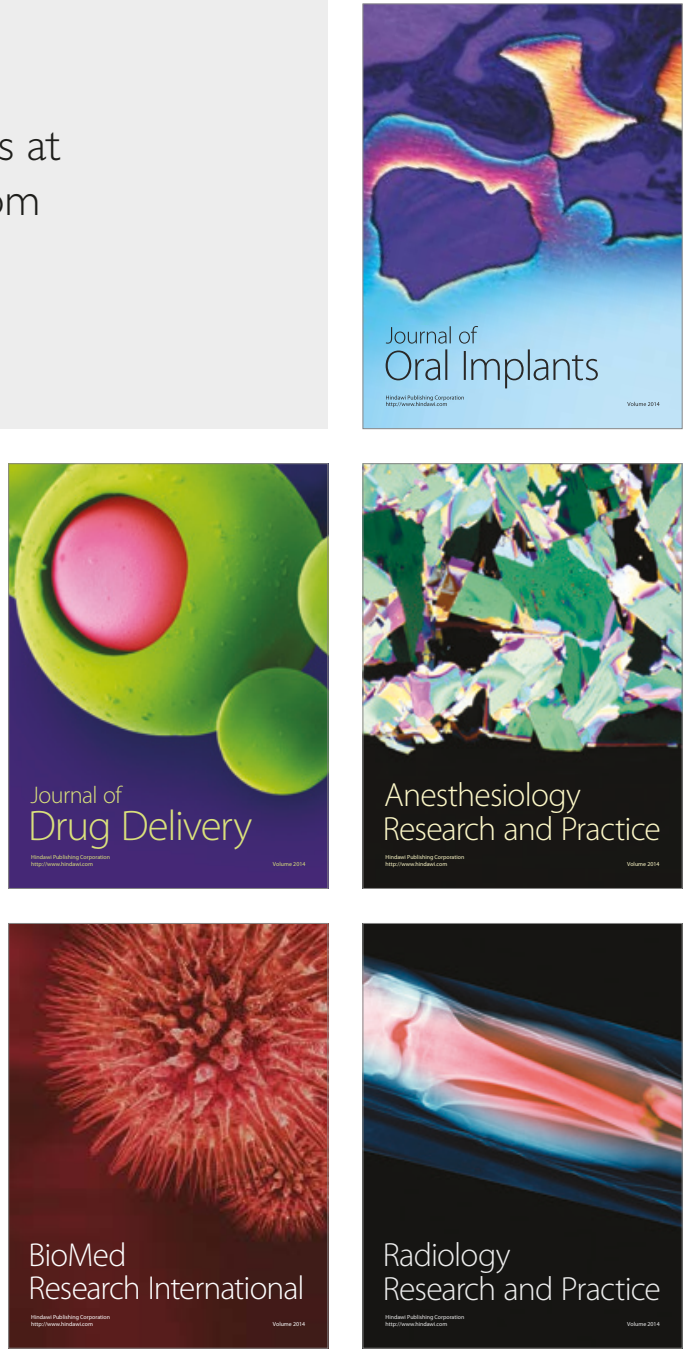